\title{
Development and preliminary validation of Brace Questionnaire (BrQ): a new instrument for measuring quality of life of brace treated scoliotics
}

\author{
Elias Vasiliadis*1, Theodoros B Grivas ${ }^{1}$ and Konstantina Gkoltsiou ${ }^{2}$
}

Address: ${ }^{1}$ Orthopaedic Department, "Thriasion" General Hospital, G. Gennimata Av. 19600, Magoula, Attica, Greece and 22 Pediatric Department, Children's Hospital, "P.\&A. Kyriakou", University of Athens Medical School, Thivon \& Levadias, Goudi, 11527, Athens, Greece

Email: Elias Vasiliadis* - nadel@otenet.gr; Theodoros B Grivas - grivastb@panafonet.gr; Konstantina Gkoltsiou - kgoltsiou@med.uoa.gr

* Corresponding author

Published: 20 May 2006

Scoliosis 2006, I:7 doi:10.1186/1748-7|61-1-7
Received: 04 March 2006

Accepted: 20 May 2006

This article is available from: http://www.scoliosisjournal.com/content///I/7

(c) 2006 Vasiliadis et al; licensee BioMed Central Ltd.

This is an Open Access article distributed under the terms of the Creative Commons Attribution License (http://creativecommons.org/licenses/by/2.0), which permits unrestricted use, distribution, and reproduction in any medium, provided the original work is properly cited.

\begin{abstract}
Background: The quality of life among children with idiopathic scoliosis during their adolescence has been reported to be affected by the brace itself. However, a controversy exists whether brace treated scoliotics experience a poor quality of life, thus there is a need for the development of a brace-oriented instrument, as the now-existing questionnaires that are commonly used, such as the SRS -22, take into consideration the effects of both the conservative and the surgical treatment on quality of life of scoliotic children. The aim of the present study is to assess the validity and reliability of Brace Questionnaire (BrQ), a new instrument for measuring quality of life of scoliotic adolescents who are treated conservatively with a brace.
\end{abstract}

Material-method: Methodology of development involved literature review, patient and health care professionals' in-depth interviews and content validity analysis on patients. A validation study was performed on 28 brace treated scoliotic children aged between 9 and 18 years old. BrQ was assessed for the following psychometric properties: item convergent validity, floor and ceiling effects, internal consistency reliability, clinical validity and responsiveness to change.

Results: $\mathrm{BrQ}$ is self administrated and developmentally appropriate for ages 9 to 18 years old and is consisted of 34 Likert-scale items associated with eight domains: general health perception, physical functioning, emotional functioning, self esteem and aesthetics, vitality, school activity, bodily pain and social functioning of scoliotic children treated conservatively with a brace. The subscales of these eight dimensions can be combined to produce a total score. Higher scores mean a better quality of life. An item convergent validity $\geq 0.40$ was satisfied by all items in the present study. A satisfactory internal consistency reliability for the BrQ was recorded (Cronbach's alpha coefficient was 0.82 ). There were no floor or ceiling effects. The correlation between $\mathrm{BrQ}$ overall scores and mild and moderate scoliosis was statistically significant $(p<0.00 \mathrm{I})$, revealing high clinical validity. An increase in effect sizes for the patient with improved scoliotic curves indicates that the $\mathrm{BrQ}$ is responsive to change in health status.

Conclusion: $\mathrm{BrQ}$ is reliable, valid and responsive to change in adolescents with IS who are treated conservatively with a brace. 


\section{Background}

An increased emphasis on outcome measures of various treatment methods has evolved in the recent years. There is a need to measure outcomes as a simple part of an effort to quantify and then improve the quality of health care. In order to determine the effectiveness of a specific treatment, numerous objective measures have been utilized, such as physical examination findings, radiographs and various non-validated functional scales. Quality of Life (QoL) as a multidimensional construct composed of functional, physical, emotional, social and spiritual wellbeing [1] has been introduced in the recent years. Traditional outcome measures are only one aspect of the overall QoL of a specific individual although there are a variety of opinions regarding the factors that contribute to QoL.

The consideration of QoL in clinical studies and various attempts to make this construct measurable to determine therapeutic success is an ongoing process [2]. It simultaneously acts as an aid for decisions on the choice of treatment strategy for chronically ill patients [3], which is obviously a challenging therapeutic aim and is at least as significant as somatic parameters [4]. QoL has therefore become a leading criterion in many outcome studies alongside physical and economic factors. In the course of this development, the concept of QoL is clearly listed as outcome parameter in many medical societies' guidelines.

Instruments that have been constructed for quantification of QoL are divided into generic, which are related to aspects that exist independently from any particular disease and disease specific, which focus on particular characteristics of specific diseases. An advantage of disease specific instruments is the precise recording of strains and limitations of a specific disease rather than those of diseases in general. The majority of current recommendations by health economists and clinical pharmacological associations include suggestions regarding the use of disease specific than generic QoL questionnaires.

AIS is considered a possible social problem and furthermore brace treatment may influence the QoL of the adolescents. There is also an increased parental concern mainly about future pain and disability as an adult [5]. Cosmetic/aesthetic results have also been an important factor to consider in the treatment of adolescent patients with scoliosis [6,7]. AIS and bracing are not associated directly with pain but they can cause discomfort and are disturbing the patient's day-life activities. In a retrospective study, $23 \%$ of 2442 patients with idiopathic scoliosis (age 6-20 years) experienced back pain [8].

Approximately $9 \%$ of girls will discontinue therapeutic brace wearing because of psychological distress related to the deformity around the hips [9]. It has been suggested that AIS may lead to multiple physical and psychosocial impairments depending on its severity [10]. Previous studies have only assessed generic health measures, functional status, body image, and self-image [10].

Braces in Adolescent Idiopathic Scoliosis (AIS) treatment are reported to produce stress [11-14] although there is a controversy whether health related QoL of brace treated scoliotics is negatively affected [10,13,15-17]. AIS is a chronic condition that affects the body configuration of the adolescent leading to certain alterations in lifestyle as a consequence. The impact of the brace to the self and body image of the adolescent is reported as the main contributory factor for stress production [18-25].

Although there are a few questionnaires for patients with AIS, a disease-specific questionnaire for brace treated children does not exist. There is a need for the development of a new brace-oriented instrument, as the questionnaires that are commonly used, such as the SRS -22, take into consideration the effects of the surgical treatment on QoL of scoliotic children. The new instrument would provide the physician a valid way to measure outcomes in order to apply the most appropriate care and to satisfy the patient's expectations in regard to the problems that the brace might produce on him or her. The aim of the present study is to assess the validity and reliability of Brace Questionnaire (BrQ), a new instrument for measuring QoL of scoliotic children who are treated conservatively with a brace.

\section{Method and material The questionnaire}

The development was initiated by thorough literature review and by the formation of potential brace-related items on the basis of the results of a series of patient and health care professionals' (psychologists, social workers, health visitors, orthotics and orthopaedic surgeons) indepth interviews.

The questions were collected and the most appropriate ones were selected by the authors and then they were grouped to eight specific domains, namely a) general health perception, b) physical functioning, c) emotional functioning, d) self-esteem and aesthetics, e) vitality, f) school activity, g) bodily pain and h) social functioning, Table 1 It was ensured that all the items chosen were consistent with the need-based theory of QoL [26]. Furthermore the items were formulated so that they could be meaningfully answered with the following five response categories: "Always", "Most of the time", "Sometimes", "Almost Never" and "Never". The procedure of selection which in fact was a first step of item reduction involved the exclusion of questions that were not relevant to QoL or items that were covering similar themes. 
Table I: The BrQ domains and the results of tests of item convergent validity, item consistency reliability and floor and ceiling effects for each domain of the BrQ

\begin{tabular}{lccccc}
\hline \multicolumn{1}{c}{ BrQ Domains } & Number of items & $\begin{array}{c}\text { Item convergent } \\
\text { validity }\end{array}$ & $\begin{array}{c}\text { Internal consist- } \\
\text { ency reliability }\end{array}$ & Floor effectsc $^{\mathbf{b}}$ & Ceiling effects $^{\mathbf{d}}$ \\
\hline $\begin{array}{l}\text { General health } \\
\text { perception }\end{array}$ & 2 & $100 \%$ & 0.72 & $0(0.0 \%)$ & $1(3.6 \%)$ \\
$\begin{array}{l}\text { Physical functioning } \\
\text { Emotional functioning }\end{array}$ & 7 & $100 \%$ & 0.80 & $0(0.0 \%)$ & $0(0.0 \%)$ \\
Self esteem and & 5 & $100 \%$ & 0.77 & $0(0.0 \%)$ & $0(0.0 \%)$ \\
aesthetics & 2 & $100 \%$ & 0.88 & $0.0 \%)$ & $0(0.0 \%)$ \\
Vitality & 2 & $100 \%$ & 0.84 & $0(0.0 \%)$ & $0(0.0 \%)$ \\
School activity & 3 & $100 \%$ & 0.82 & $0(0.0 \%)$ & $3(10.7 \%)$ \\
Bodily pain & 6 & $100 \%$ & 0.85 & $0(0.0 \%)$ & $3(7.1 \%)$ \\
Social functioning & 7 & $100 \%$ & 0.88 & & $3(10.7 \%)$ \\
\hline
\end{tabular}

a Percentage of item-scale correlations $\geq 0.40$.

b Cronbach's alpha coefficient

c Percentage of respondents with minimum scale scores

d Percentage of respondents with maximum scale scores

\section{The studied population}

A validation study was performed in order to reduce the number of items through psychometric analysis and to perform content validity of the questionnaire on patients. The validation study involved 28 scoliotic children conservatively treated with a Dynamic Derotation Brace, a modified Boston brace with antirotatory blades [27]. All the 28 children are followed at the Scoliosis Clinic of the Orthopaedic Department of Thriasio General Hospital of Athens, Greece. Seventeen out of 28 children had right thoracic and left lumbar curves with a mean age 13.3 years (range 9-17), 15 girls and 2 boys with a mean thoracic Cobb angle $23.2^{\circ}$ (range $10^{\circ}-38^{\circ}$ ) and a mean lumbar $21.2^{\circ}$ (range $8^{\circ}-36^{\circ}$ ) respectively. Rotation was measured at a mean value of $6.9^{\circ}$ (range $3^{\circ}-25^{\circ}$ ) for the thoracic curve and $7.8^{\circ}$ (range $4^{\circ}-15^{\circ}$ ) for the lumbar curve. Four out of 28 children (all girls) had right thoracic curves with a mean age 13.8 years (range $12-15$ years). Mean thoracic Cobb angle was $25^{\circ}$ (range $22^{\circ}-35^{\circ}$ ) and a mean apical vertebral rotation $6.8^{\circ}$ (range $3^{\circ}-10^{\circ}$ ). Seven out of 28 children ( 6 girls and 1 boy) had thoracolumbar curves with a mean age 13.5 years (range $12-18$ years), with a mean Cobb angle $24^{\circ}$ (range $20^{\circ}-38^{\circ}$ ) and a mean apical vertebral rotation $10^{\circ}$ (range $4^{\circ}-30^{\circ}$ ).

\section{Psychometric evaluation}

The BrQ was assessed for the following psychometric properties: item convergent validity (item-scale correlations should be $\geq 0.4$ ) [28], floor and ceiling effects (the percentage scoring the lowest and highest possible scores), internal consistency reliability (estimates how consistently individuals respond to the items within a scale and is measured with Cronbach's alpha), clinical validity and responsiveness to change.
The clinical validity of the BrQ was assessed by describing and comparing BrQ overall scores of the children according to the severity of their scoliosis. The patients were divided to mild and moderate subgroups if their major curve was below or higher than $30^{\circ}$ respectively. Fifteen patients were in the mild and 13 were in the moderate subgroup. The hypothesis was that patients with more severe curves would have worse QoL, indicated by lower BrQ overall scores.

The responsiveness of the $\mathrm{BrQ}$ to change over time was assessed by comparing BrQ overall change scores among patients defined as improved, stable and deteriorated from baseline to re-evaluation during the follow up period, on the basis of their curve change. The criterion for improvement or deteriorating of a curve was a Cobb angle change $>5^{\circ}$ compared with the initial reading on the radiographs [29] with the child out of brace. Re-evaluation was performed at least 2 years after the initiation of brace treatment. The BrQ was filled always prior to clinical evaluation or any discussion with the physician.

The effect size (ES) was used as a measure of the change in BrQ overall scores within each group. Effect sizes were calculated by dividing the change in mean BrQ overall scores by the standard deviation of mean scores at baseline. The ES has been recommended in the literature as an appropriate point of reference for evaluating the magnitude and meaning of change in health status measures [30].

\section{Statistical analysis}

Kolmogorov-Smirnov goodness-of-fit test and ShapiroWilk test for normality did not find the analysis data to be normally distributed; therefore non-parametric tests were used for the statistical analysis. Pearson's correlation coefficient was used for all correlations evaluated; the 
Table 2: Floor and ceiling effects (percentage of respondents with minimum/maximum scale scores) for each item of the BrQ

\begin{tabular}{|c|c|c|}
\hline No of Item & Floor effect & Ceiling effect \\
\hline I & I (3.58\%) & $2(7.14 \%)$ \\
\hline 2 & $0(0.00 \%)$ & 2 (7.| $14 \%)$ \\
\hline 3 & $2(7.14 \%)$ & $0(0.00 \%)$ \\
\hline 4 & $2(7.14 \%)$ & I (3.58\%) \\
\hline 5 & $3(10.71 \%)$ & $0(0.00 \%)$ \\
\hline 6 & I (3.58\%) & $2(7.14 \%)$ \\
\hline 7 & I (3.58\%) & I (3.58\%) \\
\hline 8 & $0(0.00 \%)$ & 2 (7.| $4 \%)$ \\
\hline 9 & I (3.58\%) & 2 (7.14\%) \\
\hline 10 & I (3.58\%) & I (3.58\%) \\
\hline 11 & I (3.58\%) & I (3.58\%) \\
\hline 12 & I (3.58\%) & $0(0.00 \%)$ \\
\hline 13 & $0(0.00 \%)$ & $2(7.14 \%)$ \\
\hline 14 & $0(0.00 \%)$ & 3 (10.7I\%) \\
\hline 15 & I (3.58\%) & I (3.58\%) \\
\hline 16 & I (3.58\%) & $0(0.00 \%)$ \\
\hline 17 & $0(0.00 \%)$ & $0(0.00 \%)$ \\
\hline 18 & $0(0.00 \%)$ & $0(0.00 \%)$ \\
\hline 19 & $0(0.00 \%)$ & 5 (I7.86\%) \\
\hline 20 & I (3.58\%) & 4 (14.29\%) \\
\hline 21 & $0(0.00 \%)$ & 3 (10.7I\%) \\
\hline 22 & $0(0.00 \%)$ & 4 (14.29\%) \\
\hline 23 & I (3.58\%) & 3 (10.7I\%) \\
\hline 24 & I (3.58\%) & 3 (10.7I\%) \\
\hline 25 & $0(0.00 \%)$ & $0(0.00 \%)$ \\
\hline 26 & $0(0.00 \%)$ & $0(0.00 \%)$ \\
\hline 27 & I (3.58\%) & 2 (7.14\%) \\
\hline 28 & I (3.58\%) & 3 (10.7I\%) \\
\hline 29 & I (3.58\%) & 4 (14.29\%) \\
\hline 30 & I (3.58\%) & 3 (10.7I\%) \\
\hline 31 & I (3.58\%) & 5 (I7.86\%) \\
\hline 32 & $0(0.00 \%)$ & $4(14.29 \%)$ \\
\hline 33 & I (3.58\%) & $3(10.71 \%)$ \\
\hline 34 & $2(7.14 \%)$ & I (3.58\%) \\
\hline
\end{tabular}

Kruskall-Wallis test was used for comparisons between more than two groups; the Mann-Whitney-Wilcoxon test was used for comparisons between pairs of groups and the Wilcoxon signed rank test was used for comparing two points in time within groups. $\mathrm{P}$ values of less than 0.05 were considered to be significant. Internal consistency was evaluated by Cronbach's alpha method.

\section{Results}

\section{The questionnaire}

A final 34 Likert scale items questionnaire was constructed. The questionnaire was designed to be self administrated and developmentally appropriate for ages 9 to 18 years old. Administration of the BrQ lasted 10-12 minutes. The English translation of the resulting 34 items of the BrQ is provided in Appendix 1, Additional file 1.

Scoring of BrQ is simple. For items 4, 5, 6, 12, 14, 15, 16 and 17 "Always" received a score of 5, "Most of the time" received a score of 4 , "Sometimes" received a score of 3 ,
"Almost Never" received a score of 2 and "Never" received a score of 1 . For items 1, 2, 3, 7, 8, 9, 10, 11, 13, 18, 19, $20,21,22,23,24,25,26,27,28,29,30,31,32,33$ and 34 "Always" received a score of 1 , "Most of the time" received a score of 2, "Sometimes" received a score of 3, "Almost Never" received a score of 4 and "Never" received a score of 5. Each item score is then multiplied by 20 and the total score is divided by 34 . The minimum score is theoretically 20 and the maximum is 100 . A higher score indicates better QoL. A subscale score can be calculated for each of the eight domains by means of dividing the total score of each dimension divided by the number of items that comprise it. A computer program has been developed for the calculation of the overall and the subscales' score of the BrQ.

\section{Factor analysis}

The results of the content validity analysis demonstrated excellent reliability and content validity for the BrQ, as summarized in Table 1. 


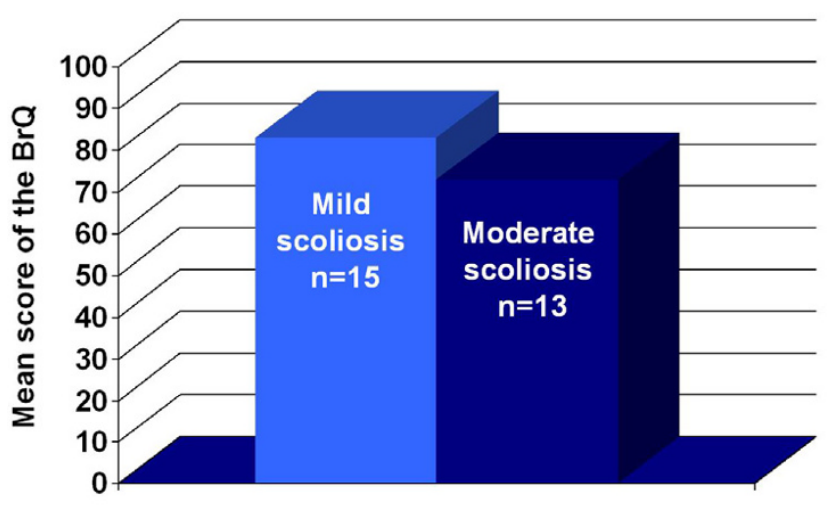

\section{Figure I}

Clinical validity. Comparison of $\mathrm{BrQ}$ overall scores for mild and moderate scoliosis subgroups (see text). $\mathrm{p}<0.00$ I (Mann-Whitney-Wilcoxon test comparing the two subgroups).

\section{Item convergent validity}

The criterion for item convergent validity (item-scale correlations $\geq 0.40$ ) was satisfied by all items in the present study. The item convergent validity for each domain of the BrQ is shown in Table 1

\section{Internal consistency reliability}

Cronbach's alpha coefficients for the BrQ overall score were 0.82 , exceeding the minimum recommended standard of 0.70 and indicating satisfactory internal consistency reliability for the BrQ. Cronbach's alpha coefficients for each BrQ domain is shown in Table 1

\section{Floor and ceiling effects for the BrQ overall score}

For the BrQ overall score, in the present study, $0 \%$ of patients scored at floor and $0 \%$ scored at ceiling. Therefore, there were no floor or ceiling effects for the BrQ overall score. Floor and ceiling effects for each domain of the BrQ are shown in Table 1 Floor and ceiling effects for each item are shown in Table 2

\section{Clinical validity}

Clinical validity was assessed by examining the correlation between BrQ overall scores and severity of the scoliotic curve. Fifteen patients with a mean age of 13 years old (9-17 years old) and a mean Cobb angle of $20.2^{\circ}\left(18^{\circ}\right.$ $29^{\circ}$ ) were in the mild subgroup and 13 patients with a mean age of 13.9 years old (12-18 years old) and a mean Cobb angle of $32.4^{\circ}\left(30^{\circ}-38^{\circ}\right)$ were in the moderate subgroup. The correlation between BrQ overall scores for mild and moderate scoliosis was statistically significant ( $\mathrm{p}$ $<0.001$ ), Figure 1 Impairment in QoL due to the brace was greater for subgroups with greater scoliotic curves. The differences between pairs of adjacent subgroups were assessed further using the Mann-Whitney-Wilcoxon test. Nevertheless, statistically significant differences in BrQ overall scores between the two subgroups, $<30^{\circ}$ and $>30^{\circ}$, was observed $(\mathrm{p}<0.001)$. These findings provide evidence that the BrQ is clinically valid in this clinical trial population, Table 1

\section{Responsiveness to change over time}

Ten patients (35\%) with a mean age of 12,9 years old ( $12-$ 17 years old) and a mean Cobb angle of $17,1^{\circ}\left(12^{\circ}-25^{\circ}\right)$ were improved, 13 patients (46\%) with a mean age of 13,4 years old (12-18 years old) and a mean Cobb angle of $24,2^{\circ}\left(20^{\circ}-36^{\circ}\right)$ were stable and 5 patients (18\%) with a mean age of 14,5 years old (9-16 years old) and a mean Cobb angle of $32^{\circ}\left(26^{\circ}-38^{\circ}\right)$ were deteriorated. The responsiveness of the $\mathrm{BrQ}$ to change over time was suggested by moderate and statistically significant correlations of BrQ overall change scores among patient with improved, stable and increased curves during the follow up period, Figure 2 A step-wise increase in effect sizes for the improved, stable and deteriorated subgroup indicating greater improvements in $\mathrm{BrQ}$ overall scores for the more improved subgroups compared with the stable and deteriorated subgroups. ES has indicated large improvements in overall scores in the improved subgroup (ES = 1.49) moderate improvements in the stable subgroup (ES $=0.68)$ and small improvements in the deteriorated subgroup ( $\mathrm{ES}=0.41)$, Table 3 These findings indicate that the $\mathrm{BrQ}$ is responsive to clinician-rated changes in health status.

\section{Missing data}

Missing data for each of the items of the BrQ ranged from $0 \%$ missing data for items $1-10,12-28,30-34$ to $3.57 \%$ ( $n=1)$ for items 11 ("You felt worried because of the brace") and 29 ("Your friends felt compassion for you"). Therefore, missing data at the item level were not problematic.

\section{Discussion}

Beyond definition, quality in health care is determined by the application of the right method of care to the patient's condition in the most effective manner possible and by the nature of the interaction between the patient and the provider [31]. This subjective aspect of quality is the portion of the outcome measures that BrQ is attempting to quantify.

Climent and Sanchez in their study of adolescents with spinal deformities contended that QoL variables include the Risser sign, clinical diagnosis, duration of brace treatment, and degree of correction [32]. These variables do not constitute a significant measurement of patient wellbeing, are more related to the diagnostic evaluation and do nothing to alter one's perception of happiness. Health 
Table 3: Changes in BrQ overall scores among patients defined as improved, stable and deteriorated from baseline to re-evaluation during the follow up period, at least 2 years after the initiation of brace treatment on the basis of their curve change. Effect sizes were calculated by dividing the change in mean score by the standard deviation of the first mean score of the BrQ.

\begin{tabular}{lcccccc}
\hline $\begin{array}{c}\text { Subgroups } \\
\text { according to the } \\
\text { curve change }\end{array}$ & $\mathbf{n}$ & $\begin{array}{c}\text { First BrQ } \\
\text { overall score } \\
\text { mean }\end{array}$ & $\begin{array}{c}\text { First Standard } \\
\text { Deviation } \\
\text { (total) }\end{array}$ & $\begin{array}{c}\text { Follow up BrQ } \\
\text { overall score } \\
\text { mean }\end{array}$ & $\begin{array}{c}\text { Mean score } \\
\text { change }\end{array}$ & $\begin{array}{c}\text { Effect Size } \\
\text { Improved }\end{array}$ \\
Imtable & 10 & 64 & 14.77 & 86 & 22 & 1.49 \\
Increased & 13 & 61 & 14.77 & 71 & 6.68 & 0.41 \\
\hline
\end{tabular}

educators, school nurses, and clinicians need to be aware of social well-being factors, and how these factors relate to psychosocial functioning [33].

In order to evaluate the effectiveness of brace treatment, we need to determine three major factors, namely the patient, the multidisciplinary team that provides care and the brace itself. Although it would seem intuitive that a patient's physical, emotional, and social well-being would all have a powerful effect on his or her ability to benefit from brace treatment, there has been little research on this

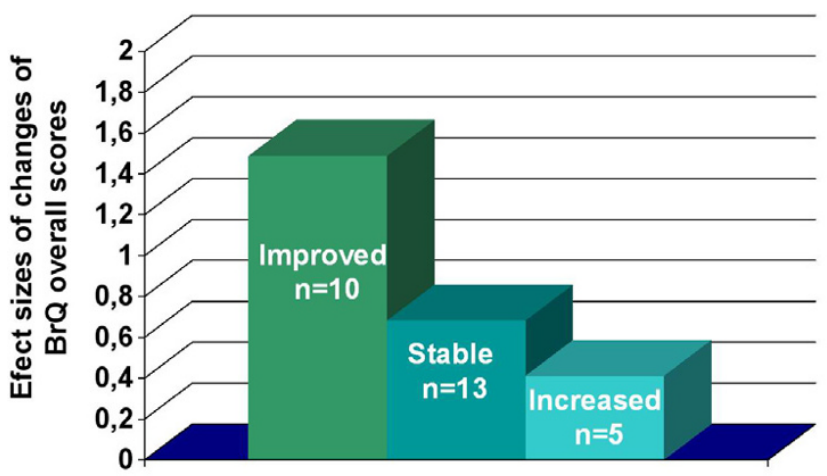

\section{Figure 2}

Responsiveness. Effect sizes as a measure of the change in $\mathrm{BrQ}$ overall change scores among patient with improved, stable and increased curves during the follow up period (see text). $\mathrm{P}<0.00$ I for comparisons of the change in $\mathrm{BrQ}$ overall scores among the three subgroups (Kruskall-Wallis test).

important determinant of brace effectiveness. The conservative treatment that is provided by the team of professionals is the method. The brace is the mean. There are very few data indicating that improvements in the type of the brace have a significant effect on the patient's QoL.

In this study we have described the development and preliminary validation of the $\mathrm{BrQ}$, a questionnaire to measure the effect of brace in conservatively treated children with AIS. To our knowledge this is the first questionnaire specifically developed and validated to measure clinical success in the management of AIS patients with a brace. The items were generated by literature search and interviewing clinicians and patients. Items were thereafter selected on their clinical importance and were grouped to eight domains.

It could be argued that a possible bias was present in the item selection phase. While we cannot rule out that some kind of biased selection of items may have been present during one or more steps of the development of the questionnaire, we find it important to underline that in our view selection of items is always a qualitative process, and thus somehow subjective. However, the resulting instrument has been subjected to a quantitative analysis based on classical test theory approaches with fairly acceptable results [34].

A specific instrument such as BrQ has its self-evident strengths as compared with generic instruments by virtue of its increased sensitivity to the unique problems related to the brace itself.

Minimal important differences or minimal important change over time were not examined for the BrQ scales. Knowledge of minimal important differences are important for interpreting the meaning of health related QoL results, thus, in future studies some attempt should be made to define minimal important differences for the BrQ.

The internal consistency reliability of items in the BrQ overall score was acceptable, with Cronbach's coefficients exceeding the accepted standard $(\geq 0.70)$. There were no floor or ceiling effects in the present study.

BrQ overall score was able to distinguish between patients with mild and moderate scoliosis. The results indicate that patients with moderate scoliosis also had lower BrQ overall scores (poorer QoL). Adolescents with severe scoliosis were excluded from the study because these patients are considered potential candidates for surgical correction, thus other specific instruments such as SRS 22 would be applied [35]. 
The responsiveness of the BrQ to change over time was confirmed by comparing change scores from two different measurements, at the initiation of treatment and at follow up. Correlation of changes in BrQ overall score in patients with improved, stable and increased curves was statistically significant. BrQ overall change scores were able to distinguish between these subgroups at a statistically significant level. ES's indicated the improvements were always greater in those patients rated as "improved" but only small or moderate in those rated as "stable". Sample sizes for the three groups were small and results for these subgroups should be interpreted with caution. The sensitivity of the BrQ to change could not be fully evaluated in this study owing to the small sample size and should be investigated further in a larger sample of patients. Therefore, responsiveness to change of the BrQ will be assessed with further research.

\section{Conclusion}

In conclusion, the BrQ is reliable, valid and responsive to change in children with AIS who are treated conservatively with a brace. BrQ takes only 10 minutes to complete and covers most of the aspects of life affected by the brace.

\section{Authors' contributions}

EV built the structure of the BrQ, was responsible for the methodological setting of the study, performed the statistical analysis and has written most parts of the manuscript. TBG was the clinical supervisor, conceived the idea of creating $\mathrm{BrQ}$, designed the study, performed part of literature review and revised the manuscript for important intellectual content. KG performed part of literature review, conducted analyses, built the structure of the BrQ and contributed to the manuscript drafting. All authors have read and approved the final manuscript.

\section{Additional material}

\section{Additional File 1}

The Brace Questionnaire The English translation of the BrQ items. BrQ is validated only in its original Greek version.

Click here for file

[http://www.biomedcentral.com/content/supplementary/17487161-1-7-S1.pdf]

\section{Acknowledgements}

The authors would like to express their thanks to Mrs. Christina Maziotou and Miss Akrivi Arvaniti for interviewing the children and collecting the data for the study and Miss Artemis Griva for reviewing and commenting on this article.

\section{References}

I. Gill TM, Feinstein AR: A critical appraisal of the quality of quality-of-life measurements. JAMA 1994, 272:619-629.
2. Ostermann T, Büssing A, Beer AM, Matthiessen PF: The Herdecke questionnaire on quality of life (HLQ): Validation of factorial structure and development of a short form within a naturopathy treated in-patient collective. Health and Quality of Life Outcomes 2005, 3:40.

3. Spitzer WO: State of science 1986: Quality of life and functional status as target variables for research. Journal of Chronic Diseases 1987, 40:465-47I.

4. Frost MH, Sloan JA: Quality of life measurements: a soft outcome-or is it? Am J Manag Care 2002, 8:574-9.

5. Bridwell KH, Shufflebarger HL, Lenke LG, Lowe TG, Betz RR, Bassett GS: Parents' and patients' preferences and concerns in idiopathic adolescent scoliosis: a cross-sectional pre-operative analysis. Spine 2000, 25:2392-2399.

6. Theologis TN, Jefferson RJ, Simpson AH, Turner-Smith AR, Fairbank JC: Quantifying the cosmetic defect of adolescent idiopathic scoliosis. Spine 1993, I8:909-9|2.

7. Grivas TB: Surgery is performed for cosmetic reasons. Stud Health Technol Inform 2002, 88: I 16-22.

8. Ramirez N, Johnston CE, Browne RH: The prevalence of back pain in children who have idiopathic scoliosis. J Bone Joint Surg 1997, 79A:364-8.

9. Korovessis P, Stamatakis M, Baikousis A, Kirkos C, Kavouris A: Vertical transmission of the hip rolls due to wearing of TLSO for scoliosis. J Spinal Disord 1996, 9:326-333.

10. Freidel K, Reichel D, Steiner A, Warschburger P, Petermann F, Weiss HR: Idiopathic scoliosis and quality of life. Stud Health Technol Inform 2002, 88:24-9.

II. Clayson D, Luz-Alterman S, Cataletto M, Levine DB: Long term psychological sequalae of surgically versus nonsurgically treated scoliosis. Spine 1984, I 2(I 0):983-986.

12. MacLean WE, Green NE, Pierre CB, Ray DC: Stress and Coping with scoliosis, Psychological effects on adolescents and their families. Journal of Paediatric Orthopaedic 1989, 9(3):257-26I.

13. Payne WK 3rd, Ogilvie JW, Resnick MD, Kane RL, Transfeldt EE, Blum RW: Does scoliosis have a psychological impact and does gender makes a difference? Spine 1997, 22(I2):1380-4.

14. Saccomani L, Vercellino F, Rizzo P, Becchetti S: Adolescents with scoliosis: psychological and psychopathological aspects. Minerva Pediatrica 1998, 50(I-2):9-14.

15. Freidel K, Petermann F, Reichel D, Steiner A, Warschburger P, Weiss HR: Quality of Life in Women With Idiopathic Scoliosis. Spine 2002, 27(4):87-9I.

16. Ugwonali OF, Lomas G, Choe JC, Hyman JE, Lee FY, Vitale MG, Roye DP Jr: Effect of bracing on the quality of life of adolescents with idiopathic scoliosis. Spine 2004, 4(3):254-60.

17. Danielsson AJ, Wiklund I, Pehrsson K, Nachemson AL: Healthrelated quality of life in patients with adolescent idiopathic scoliosis: a matched follow-up at least $\mathbf{2 0}$ years after treatment with brace or surgery. Eur Spine J 200 I, 1 0(4):278-88.

18. Liskey-Fitzwater N, Moore CL, Gurel LM: Clothing importance and self perception of female adolescents with and without scoliosis. Clothing and Textiles Research Journal 1993, I I:17-22.

19. Bengtsson G, Fallstrom K, Jansson B, Nachemson A: A psychological and psychiatric investigation of the adjustment of female scoliosis patients. Acta Psychiatrica Scandinavica I974, 50(I):50-59.

20. Wickers FC, Bunch WH, Barnet PM: Psychological factors in failure to wear the Milwaukee brace for treatment of idiopathic scoliosis. Clinical Orthopaedics and Related Research 1977, I 26:62-66.

21. Eliason MJ, Richman LC: Psychological effects of idiopathic adolescent scoliosis. Journal of Developmental and Behavioural Pediatrics 1984, 5(4): 169-172.

22. Fallstrom K, Cochran T, Nachemson A: Long term effects on personality development in patients with adolescent idiopathic scoliosis. Influence of type of treatment. Spine 1986, I I (7):756-758.

23. Goldberg M, Mayo N, Politas B, Scott S, Hanley J: The ste-jastine adolescence idiopathic scoliosis cohort study, Part II, Perception of health, self and body image and participation in physical activities. Spine 1994, 19(14): I562-1572.

24. Sapountzi-Krepia D, Valavanis J, Panteleakis GP, Zangana DT, Vlachojiannis PC, Sapkas GS: Perceptions of body image, happiness and satisfaction in adolescents wearing a Boston brace for scoliosis treatment. Journal of Advanced Nursing 200I, 35(5):683-690. 
25. Reichesl D, Schanz J: Developmental psychological aspects of scoliosis treatment. Pediatric Rehabilitation 2003, 6(3-4):22I-225.

26. Hunt SM, McKenna SP: The QLDS: a scale for the measurement of quality of life in depression. Health Policy 1992, 22:307-319.

27. Grivas TB, Vasiliadis E, Chatziargiropoulos T, Polyzois VD, Gatos K: The effect of a modified Boston brace with anti-rotatory blades on the progression of curves in idiopathic scoliosis: aetiologic implications. Pediatr Rehabil 2003, 6(3-4):237-42.

28. Campbell DT, Fiske DW: Convergent and discriminant validation by the multitrait-multimethod matrix. Psychol Bull 1959, 56:81-105.

29. Soucacos PN, Zacharis K, Gelalis J, Soultanis K, Kalos N, Beris A, Xenakis T, Johnson EO: Assessment of curve progression in idiopathic scoliosis. Eur Spine J 1998, 7(4):270-277.

30. Kazis LE, Anderson J], Meenan RF: Effect Sizes for interpreting changes in health Status. Med Care 1989, 27(Suppl): 178-189.

31. Blumenthal D: Quality of health care: Part I. Quality of care. What is it? N Engl J Med 1996, 335:89|-893.

32. Climent JM, Sanchez J: Impact of the type of brace on the quality of life of adolescents with spine deformities. Spine 1999, 24:1903-1908.

33. Mirtz TA, Thompson MA, Greene L, Wyatt LA, Akagi CG: Adolescent idiopathic scoliosis screening for school, community, and clinical health promotion practice utilizing the PRECEDE-PROCEED model. Chiropractic \& Osteopathy 2005, 13:25.

34. Crocker L, Algina J: Introduction to classical and modern test theory Fort Worth, Harcourt Brace Jovanovich; 1986.

35. Asher MA, Min Lai S, Burton D, Manna B: The Reliability and Concurrent Validity of the SRS-22 Patient Questionnaire for Idiopathic Scoliosis. Spine 2003, 28:63-9.

\section{Publish with Bio Med Central and every scientist can read your work free of charge}

"BioMed Central will be the most significant development for disseminating the results of biomedical research in our lifetime. "

Sir Paul Nurse, Cancer Research UK

Your research papers will be:

- available free of charge to the entire biomedical community

- peer reviewed and published immediately upon acceptance

- cited in PubMed and archived on PubMed Central

- yours - you keep the copyright

Submit your manuscript here:

http://www.biomedcentral.com/info/publishing_adv.asp
BioMedcentral 